\title{
Outorga de uso de direito: uma revisão sobre o instrumento no Tocantins
}

A Lei no 9.433 é a responsável pelo estabelecimento da Política Nacional de Recursos Hídricos; pela criação do Sistema Nacional de Gerenciamento de Recursos Hídricos e definição dos critérios de outorga de direitos de uso dos recursos. A outorga de direito de uso de recursos hídricos é um instrumento essencial não apenas como ato administrativo de autorização de uso da água, mas uma ferramenta de controle, um instrumento que garante a segurança dos corpos hídricos diante das diversas demandas da sociedade. O objetivo desse trabalho é analisar a importância da outorga dos direitos de uso como instrumento regulador na gestão dos recursos hídricos. Existem fragilidades na utilização desse instrumento que precisam ser resolvidas para assegurar a sua eficácia na gestão dos recursos hídricos. A primeira dessas fragilidades é a fiscalização. Dadas as grandes dimensões do Brasil grande parte dos setores de fiscalização, não apenas os que regulam os recursos hídricos, enfrentam problemas de logística. Outra fragilidade é com relação ao critério de cálculo das vazões outorgáveis.

Palavras-chave: Política Nacional de Recursos Hídricos; Recursos hídricos; Outorga de direito de uso.

\section{Granting of use of rights: a review of the instrument in Tocantins}

Law No. 9433 is responsible for establishing the National Policy on Water Resources; for the creation of the National Water Resources Management System and definition of the criteria for water rights. The water rights are an essential instrument not only as an administrative act of authorization of water use, but a control tool, an instrument that guarantees the safety of water bodies in face of the diverse demands of society. The objective of this work is to analyze the importance of the water rights as a regulatory instrument in the management of water resources. There are weaknesses in the use of this instrument that need to be addressed to ensure its effectiveness in the management of water resources. The first of these weaknesses is surveillance. Given the large Brazilian dimensions, most of the inspection sectors, not only those that regulate water resources, face logistical problems. Another weakness is with respect to the criterion to the criterion of calculation of the water concessions.

Keywords: National Policy on Water Resources; Water resources; Water rights.

Topic: Engenharia de Recursos Hídricos

Reviewed anonymously in the process of blind peer.
Received: 10/11/2020

Approved: 15/02/2021

Lucas de Sena Linhares

Centro Universitário Unirg, Brasil

http://lattes.cnpq.br/9721026636791951

lucassena775@gmail.com

Felipe Martins de Aguiar

Centro Universitário Unirg, Brasil

http://lattes.cnpq.br/3357202421623561

felipemartinsjaka@gmail.com

Referencing this:

LINHARES, L. S.; AGUIAR, F. M.. Outorga de uso de direito: uma revisão sobre o instrumento no Tocantins. Natural Resources, v.11, n.1, p.3340, 2021. DOI: http://doi.org/10.6008/CBPC2237-9290.2021.001.0005 


\section{INTRODUÇÃO}

Desde meados do século XX o Direito e organizações internacionais reconhecem a necessidade de o acesso a água ser compreendido como um direito básico do ser humano, mas apenas no século posterior esse direito foi de fato reconhecido, vista a necessidade de proteger determinados grupos sociais em condições de vulnerabilidade (BOLSON et al., 2016).

Essa mudança foi fortemente influenciada pelas diversas conferências internacionais e declarações sobre a água, ambiente e saúde. Destacam-se: a Conferência das Nações Unidas sobre a Água, em 1977; a Conferência Internacional sobre Água e o Meio Ambiente sediada em Dublin, 1992; e a Conferência Internacional sobre Água e Desenvolvimento Sustentável em Paris, 1998 (BOLSON et al., 2016).

A partir do início dá década de 2000 surgiu com muita força o tema da Governança envolvendo os recursos hídricos. A ideia de Governança pode ser compreendida como poder social mediador das relações entre Estado e Sociedade Civil, servido como ferramenta para implementação socialmente aceitável de políticas públicas e implicando no estabelecimento de um sistema de regras, normas e condutas que reflitam os valores e visões dos indivíduos sobre determinado assunto. Assim a Governança da água é um plano para o fortalecimento de uma gestão democrática, integrada e compartilhada desse recurso (JACOBI et al., 2012).

A Lei das Águas do Brasil, Lei no 9.433, foi promulgada em 1997 com a finalidade de apoiar o Plano Nacional de Governança Hídrica (PNGH). A ideia primária do plano é assegurar que os usuários regulares de fontes de água sejam: outorgados por uma agência governamental; monitorados por comitês; e, finalmente, contribuintes para a preservação dos mananciais (PETTERINI, 2018).

A Lei no 9.433 é a responsável pelo estabelecimento da Política Nacional de Recursos Hídricos; pela criação do Sistema Nacional de Gerenciamento de Recursos Hídricos e definição dos critérios de outorga de direitos de uso dos recursos; e altera os percentuais da distribuição da compensação financeira devido à exploração de recursos hídricos para fins de geração de energia elétrica (BRASIL, 1997).

Essa Lei tem por objetivos: assegurar que a atual e às futuras gerações tenham a disponibilidade de água com qualidade para atender as diversas necessidades de uso; garantir que todos utilizem esse recurso de modo racional e integrada tendo em mente o desenvolvimento sustentável; prevenir e defender a sociedade contra eventos hidrológicos críticos de origem natural ou decorrentes do uso inadequado dos recursos naturais; e incentivar e promover a captação, a preservação e o aproveitamento de águas pluviais (BRASIL, 1997).

Cinco instrumentos são apresentados no art. 5 da Lei como ferramentas para a implementação da Política Nacional de Recursos Hídricos. Dentre eles está a outorga dos direitos de uso de recursos hídricos. Diante disso, o objetivo desse trabalho é analisar a importância da outorga dos direitos de uso como instrumento regulador na gestão dos recursos hídricos.

\section{METODOLOGIA}

O objetivo prioritário da pesquisa é analisar a importância da outorga dos direitos de uso como 
instrumento regulador na gestão dos recursos hídricos por meio de uma revisão da literatura. Deste modo, a metodologia utilizada neste trabalho se tratou de uma revisão bibliográfica que serviu como base teórica da pesquisa e como balizador para alcanças o objetivo proposto. A pesquisa se trata de um estudo descritivo bibliográfico, que consiste na exposição das características da outorga de direito de uso da água como um instrumento de gestão. Foram analisados estudos nacionais e internacionais que abordam sobre a temática.

\section{DISCUSSÃO TEÓRICA}

A outorga de direito de uso é o instrumento da Política de Recursos Hídricos com a finalidade de garantir o controle quantitativo e qualitativo dos usos da água. Esse instrumente assegura ao usuário outorgado o direito de acesso à água, regulando seu uso em uma bacia hidrográfica (ANA, 2011).

A outorga de direito de uso de recursos hídricos é um ato administrativo de autorização, mediante o qual o poder público outorgante, que a depender do corpo hídrico é a União, o estado ou Distrito Federal, concede ao outorgado o direito de uso da água por determinado tempo, nas condições expressas no respectivo ato (SIMPLíCIO et al., 2016).

\section{A gestão dos recursos hídricos e a outorga no Brasil e no mundo}

A outorga dos direitos de uso de recursos hídricos se configura em um dos principais instrumentos de gestão e planejamento de recursos hídricos no Brasil. Sua utilização não se limita a facultar direito de uso da água ao seu detentor, mas além de possibilitar os órgãos gestores manter o controle quantitativo e qualitativo do seu uso, garante ao usuário o direito de uso da água de forma pessoal e intransferível (MOREIRA, 2006).

Apesar de a Lei no 9.433/97 determinar que a água é um recurso dotado de valor econômico a outorga é uma concessão de uso e não representa venda da água utilizada, uma vez que por conta de seu caráter público é um recurso inalienável. A outorga tem a designação de determinar quais os volumes serão outorgados, conferindo prioridade ao outorgado, ante o montante de água considerada genericamente como bem de uso comum do povo (BRASIL, 1997).

Nos Estados Unidos da América (EUA), os direitos às águas são conhecidos como water rights e variam de região para região a depender do sistema jurídico competente. Diferente da realidade brasileira em que a água é um bem domínio público e o Poder Público é o gestor, nos EUA as águas e as terras cobertas por elas pertencem aos Estados federados e, e as entidades federativas possuem tanto o domínio quanto a gestão dos recursos hídricos, desde que as suas diretrizes não conflitem com as leis gerais editadas pelo Congresso (RIBAS, 2016).

Nos EUA os bens públicos são indivisíveis e gratuitos, logo, todas as pessoas têm o direito de acesso sem custo, com exceção dos custos agregados à captação, transporte e distribuição. Os water rights concedem direitos de uso da água aos portados, contudo esses direitos não configuram qualquer título de direito real no tocante à água, que é tida como bem público (CASSUTO et al., 2011).

Os métodos estadunidenses de concessão de uso da água são basicamente dois: os riparian rights, 
direitos dos ribeirinhos em tradução livre, que consiste nos direitos reais de propriedade, mas apenas direitos ao uso das águas para fins domésticos e outros propósitos legais; e os prior appropriation, prioridade de posse (nossa tradução), esse direito de uso é baseado no princípio do first in time, first in right, ou seja, os usuários mais antigos têm prioridade no uso da água. Esse direito prioriza o primeiro uso do recurso e para garantir o direito, a pessoa deve cumprir com todas as exigências legais e utilizar a água para um propósito benéfico, como por exemplo, a produção de alimentos (RIBAS, 2016).

A maioria dos países da América do Sul nos últimos anos tem atualizado as suas legislações sobre as águas. Contudo, é comum que nesses países as leis que visam a proteção e a gestão da água possuem escassa capacidade de regulação e fiscalização, o que acentua o surgimento de conflitos e usos desiguais dos recursos hídricos (ATALC, 2016).

Na Argentina não existe uma legislação nacional de água que regule a gestão dos recursos hídricos em todo território nacional. Fica a cargo das províncias legislar sobre os aspectos ambientais e no que se relaciona aos recursos hídricos. Em geral, as leis provinciais argentinas são pouco flexíveis e não abrangem o valor econômico, social e ambiental da água. Esse modelo de gestão dos recursos hídricos se caracteriza, principalmente, por uma fragmentação setorial e institucional (CALCAGNO et al., 2000).

A Resolução 293 de 2012, da Província de Correntino na Argentina, determina que a água é um bem de domínio público e o Estado provincial é responsável pela administração dos recursos hídricos superficiais e subterrâneos. E é de responsabilidade da província conceder o direito de uso das águas para os requerentes na condição de que seu uso seja benéfico em termos de interesse público, sendo que esse uso vigora por um período adequado a depender de avaliações periódicas dos direitos de uso atribuídos (ICAA, 2012).

$\mathrm{Na}$ África do Sul a legislação relativa a gestão das águas era arraigada ao sistema de colonização do país. A lei que tratava dos recursos hídricos era baseada no princípio do direito romano e no direito holandês onde o direito de acesso à água priorizava os ribeirinhos, ou seja, os proprietários de terra adjacente à fonte de água. Essa legislação era bastante enviesada e não buscava a distribuição equitativa da água, uma vez que priorizando a distribuição a aqueles que possuíam terras atendia a população branca minoritária, que possuía cerca de $87 \%$ da terra (CASTRO, 2012).

Com propósito de resolver esse problema a África do Sul iniciou um dos mais ambiciosos processos de redistribuição de direitos de uso da água no mundo, com a reforma agrária e a revisão dos mecanismos de gerenciamento dos recursos hídricos. A nova Lei Nacional das Águas para a África do Sul prevê a autorização de uso da água de três maneiras diferentes. A primeira envolvendo usos que demandam volumes pequenos em especial, para uso doméstico e dessedentação animal. Para o uso de volumes maiores de água com algum potencial de impactos negativos sobre os recursos hídricos, existem Autorizações gerais que concedem direito de uso sem licença. Todos os demais usos exigem licença para concessão de direito de utilização, por exemplo, em atividades de captação, armazenamento, descarga efluentes em corpos hídricos, modificações na estrutura física de rios e córregos (CASTRO, 2012). 


\section{A estrutura metodológica do instrumento}

O artigo 12 a Lei das Águas determina quais os usos de recursos hídricos sujeitos a outorga e quais os usos que não dependem da outorga. Os usos que se enquadram no primeiro grupo são cinco: I. Derivação ou captação de parcela da água existente em um corpo de água para consumo final, inclusive abastecimento público, ou insumo de processo produtivo; Il. Extração de água de aquífero subterrâneo para consumo final ou insumo de processo produtivo; III. Lançamento em corpo de água de esgotos e demais resíduos líquidos ou gasosos, tratados ou não, com o fim de sua diluição, transporte ou disposição final; IV. Aproveitamento dos potenciais hidrelétricos; V. Outros usos que alterem o regime, a quantidade ou a qualidade da água existente em um corpo de água.

Os usos que não dependem da outorga, contudo sendo passíveis de cadastramento quando solicitado, são três: I. O uso de recursos hídricos para a satisfação das necessidades de pequenos núcleos populacionais, distribuídos no meio rural; II. As derivações, captações e lançamentos considerados insignificantes; III. As acumulações de volumes de água consideradas insignificantes.

A vigência máxima determinada pela Lei das Águas é de 35 anos, havendo possibilidade de exceções determinadas pela avaliação do caso. Nas águas de domínio da União, o outorgante tem o prazo de até dois anos para iniciar a implantação do projeto de uso e até seis anos para conclusão de sua implantação, após a data de publicação do ato de outorga (ANA, 2011).

Além de temporária as outorgas não são definitivas podendo haver a suspensão parcial ou total, da concessão em casos de: I. descumprimento dos termos da outorga pelo outorgado; II. Ausência de uso por três anos consecutivos; III. Necessidade de água para atender a situações de calamidade, incluindo aquelas resultantes de situações climáticas adversas; IV. Necessidade de prevenir ou reverter grave degradação ambiental; V. necessidade de atendimento a usos prioritários, de interesse coletivo, quando não se possui fontes alternativas; VI. Indeferimento ou cassação da licença ambiental; VII. necessidade de manutenção da navegabilidade do corpo d'água.

Um dos critérios considerados no processo de desenvolvimento de um sistema de outorga é a definição da vazão outorgável. Comumente se estabelece um valor de vazão durante o período de estiagem que representa o limite superior de utilização do curso d'água. Essa vazão limite passa a ser a referência para as concessões de outorgas (RIBEIRO et al., 2001). No Brasil, geralmente, essa vazão é calculada com base em dados históricos aplicados a modelos estatístico-hidrológicos adotados como bases em vazões de referência como a $\mathrm{Q}_{7,10}$, vazão mínima registrada em sete dias consecutivos e com recorrência de dez anos, e as vazões associada às permanências a $Q_{90}$ e a $Q_{95}$, vazões que em $90 \%$ ou $95 \%$ do período analisado foram mantidas iguais ou superiores, respectivamente (SANTOS et al., 2013).

Existem pesquisas que propõem adições de outros critérios, além dos comumente empregados, para a determinação do sistema de outorga, como por exemplo, o critério de prioridade de uso das águas superficiais, método que propõe a utilização prioritária de águas superficiais condicionando a utilização das águas subterrâneas às situações em que não for possível o suprimento a partir dos recursos hídricos 
acumulados na superfície (RIBEIRO et al., 2014).

\section{A outorga no âmbito Estadual}

No Estado do Tocantins, conforme determina o Decreto no 2432 de 6 de junho de 2005, a outorga do direito de uso de recursos hídricos é concedida pelo Instituto Natureza do Tocantins - NATURATINS. O NATURATINS tem a incumbência de conceder o direito de uso à medida que a deliberação estiver condicionada à disponibilidade hídrica e às prioridades expressas no Plano Estadual de Recursos Hídricos e nos Planos de Bacias Hidrográficas. A outorga tem validade de até 35 anos quando o período for coincidente à validade da concessão dos serviços públicos de abastecimento de água e de geração de energia elétrica; e até 5 anos, sendo renovável no mesmo período, consecutivamente, desde que atendidas as exigências legais e regulamentares vigentes (TOCANTINS, 2005).

A concessão das outorgas é dada após análise das demandas e a tomada de decisão para o deferimento das solicitações é auxiliada pelo sistema de apoio à decisão para outorga do direito de uso dos recursos hídricos, o SAD-Outorga. A análise de liberação realizada pelo SAD-Outorga consiste em três passos: análise da disponibilidade; a tomada de decisão; e a atualização da disponibilidade hídrica (TOCANTINS, 2016)

A análise da disponibilidade é basicamente fundamentada na vazão de referência para outorga, que no Estado é calculada com base nas informações hidrológicas da bacia hidrográfica, para uma vazão de até 90\% de permanência, com valores diários. As vazões mínimas são calculadas para três períodos no ano, com quatro meses cada, sendo: o período seco de agosto a novembro; o período norma de abril a julho; e o período chuvoso de dezembro a março. A tomada de decisão é a etapa em que se analisa o impacto da intervenção na disponibilidade hídrica, uma vez que cada tipo de intervenção, ou alteração, por concessão de outorga modifica a disponibilidade do sistema hídrico. Por fim, resta a atualização da disponibilidade hídrica após a liberação do uso dos recursos hídricos a fim de garantir o controle e a segurança hídrica do manancial levando em consideração o débito relacionado à intervenção (TOCANTINS, 2016).

\section{Eficácia do instrumento}

A ausência de uma cultura de gestão preventiva da oferta de água é umas das principais dificuldades para implementação das políticas hídricas no norte do Brasil. Quando se alia essa ausência à inexistência de dados fluviométricos nas bacias hidrográficas, a falta de cadastro de usuários de água, o desconhecimento das demandas desses usuários e o uso de metodologias que não levam em consideração as particularidades de cada bacia para o estabelecimento dos valores adequados a serem outorgados, se coloca em risco a eficácia da outorga de direito de uso da água como ferramenta de gestão (LIMA et al., 2010; MARCOLINI, 2016).

A fiscalização é uma das principais atividades exercida pelo poder público para garantir o cumprimento da legislação. É uma das atribuições da ANA a fiscalização dos usos de recursos hídricos nos corpos de água de domínio da União e, por conseguinte a responsabilidade pelos corpos hídricos estaduais 
e municipais é de designados órgãos públicos. No Tocantins essa atribuição pertence a NATURATINS. A fiscalização deve verificar o cumprimento de termos e condições previstas na outorga e em regulamentos específicos, e onde couber, identificar e autuar usuários irregulares, buscando garantir disponibilidade de água para os diferentes usos e dirimir conflitos, sobretudo em bacias críticas (ANA, 2018).

Uma das principais dificuldades dos órgãos competentes pelo controle das outorgas é, justamente, a fiscalização. Geralmente, o número de pessoas que compõem os grupos de fiscalização é muito pequeno, já as dificuldades orçamentárias e os territórios a serem fiscalizados são muito grandes. Percebe-se então uma fragilidade nesse sentido que influência diretamente na eficácia da outorga (FREIRE, 2002).

Outro critério determinante para eficácia do instrumento é o cálculo das vazões outorgáveis. A metodologia adotada pela ANA é o mesmo adotado por grande parte dos estados da federação. Contudo, a utilização desse método gera discussão entre os pesquisadores. Enquanto alguns autores acreditam que a utilização desses métodos baseados em séries temporais de vazões não considera de forma significante os aspectos ecológicos e sistêmicos dos corpos hídricos brasileiros e correndo o risco de generalizar peculiaridades de determinadas regiões do país, outros defendem que as vazões de referência, baseadas unicamente em dados hidrológicos, são suficientes para assegurar a proteção corpos hídricos (SANTOS et al., 2013; HARRIS et al., 2000; LONGHI et al., 2011).

\section{CONCLUSÕES}

A instauração da Política Nacional de Recursos Hídricos, proveniente da aprovação da Lei 9.433/97, fez avançar a Gestão dos Recursos Hídricos no Brasil. A evolução dos instrumentos de implantação dessa política é perceptível no país, principalmente, nessa era altamente interativa onde os dados e indicadores estão disponíveis ao público nas plataformas digitais dos Órgãos gestores.

A outorga de direito de uso de recursos hídricos é um instrumento essencial não apenas como ato administrativo de autorização de uso da água, mas uma ferramenta de controle, um instrumento que garante a segurança dos corpos hídricos diante das diversas demandas da sociedade.

Contudo, existem fragilidades na utilização desse instrumento que precisam ser resolvidas para assegurar a sua eficácia na gestão dos recursos hídricos. A primeira dessas fragilidades é a fiscalização. Dadas as grandes dimensões do Brasil grande parte dos setores de fiscalização, não apenas os que regulam os recursos hídricos, enfrentam problemas de logística. Em 2016 a ANA emitiu 5200 outorgas de direito de uso para captação, em 2017 esse número aumentou para 8632 outorgas e em 2018 até o dia 25/04 já foram emitidas 1051. O número reduzido de equipes frente ao número constantemente em crescimento de usuários se configura em um grande desafio para os gestores.

Outro ponto com relação a fiscalização é classificação tida como leve das atividades de derivação ou utilização dos recursos hídricos para qualquer finalidade, sem a respectiva outorga de direito de uso; e da implantação de que derivem ou utilizem recursos hídricos que implique alterações no regime, quantidade ou qualidade dos mesmos, sem a competente outorga, embora esses usos apresentem riscos diretos à segurança dos corpos hídricos. Essa classificação é determinada pela Resolução no 662, de 29 de novembro 
de 2010, da ANA.

Outra fragilidade é com relação ao critério de cálculo das vazões outorgáveis, outros países têm desenvolvido metodologias holísticas para a determinação das vazões mínimas, que são mais realistas as realidades e particularidades de suas bacias hidrográficas conforme menciona Santos et al. (2013), e o Brasil dada a sua extensão e grande diversidade regional precisa desenvolver metodologias mais adaptáveis as suas realidades, visando o aproveitamento água e a manutenção dos seus corpos hídricos.

\section{REFERÊNCIAS}

ANA. Agência Nacional de Águas. Outorga e fiscalização. ANA, 2018.

ANA. Agência Nacional de Águas. Outorga de direito de uso de recursos hídricos. Cadernos de capacitação em recursos hídricos. Brasília: SAG, 2011.

ATALC. Amigos de la Tierra América Latina y el Caribe. Informe: Estado del agua en América Latina y el Caribe. ATALC, 2016.

BOLSON, S. H.; HAONAT, A. I.. A governança da água, a vulnerabilidade hídrica e os impactos das mudanças climáticas no Brasil. Veredas do Direito, Belo Horizonte, v.13, n.25, p.223-248, 2016.

BRASIL. Lei n. 9.433, de 8 de janeiro de 1997. Institui a Política Nacional de Recursos Hídricos. Brasília: DOU, 1997.

CALCAGNO, A.; JÁUREGUI, L. U.; PLANAS, A. C.; NOVILLO, M. G.; MENDIBURO, N.. Informe sobre la gestión del agua en la Republica Argentina. Global Water Partnership, 2000.

CASSUTO, D. N.; SAMPAIO, R. S. R.. Water law in the United States and Brazil: climate change \& two approaches to emerging water poverty. Wm. \& Mary Envtl. L. \& Pol'y Rev. v.35, p.371-413, 2011.

CASTRO, C. N.. Gestão das águas: experiências internacional e brasileira. Brasília: IPEA, 2012.

FREIRE, C. C.. Outorga e cobrança: instrumentos de gestão aplicados à água subterrânea. In: CONGRESSO BRASILEIRO DE ÁGUAS SUBTERRÂNEAS, 12. Anais. Florianópolis: ABAS, 2002.

HARRIS, N. M.; GURNELL, A. M.; HANNAH, D. M.; PETTS, G. E.. Classification of river regimes: a context for hydroecology. Hydrological Processes, v.14, p.2831-2848, 2000. DOI: http://doi.org/10.1002/10991085(200011/12)14:16/17<2831::AID-HYP122>3.0.CO;2-O

ICAA. Província de Corrientes. Resolución n. 293 de $\mathbf{1 3}$ de Junio de 2012. Reglamento de Canon para Uso de las Aguas Públicas. Corrientes, Argentina, 2012.

JACOBI, P. R.; GÜNTHER, W. M. R.; GIATTI, L. L.. Agenda 21 e Governança. Estudos Avançados, v.26, n.74, p.331-339, 2012.

LIMA, A. M. M.; CRUZ, F. M.; CAVALCANTE, L. M.; CHAVES, L. M. L.; IMBIRIBA JUNIOR, M.; SANTOS, V. J. C.. A gestão da oferta hídrica no Estado do Pará e seus aspectos condicionantes. Revista Brasileira de Recursos Hídricos, v.15, n.3, p.69-83, 2010. DOI:

http://doi.org/10.21168/rbrh.v15n3.p69-83

LONGHI, E. H.; FORMIGA, K. T. M.. Metodologias para determinar vazão ecológica em rios. Revista Brasileira de Ciências Ambientais, n.20, p.33-48, 2011.

MARCOLINI, F. C. P.. A influência das captações de águas superficiais consideradas insignificantes na vazão do Ribeirão Água Fria, Palmas - TO. Dissertação (Mestrado Profissional em Engenharia Ambiental) - Universidade Federal do Tocantins, Palmas, 2016.

MOREIRA, M. C.. Gestão de recursos hídricos: sistema integrado para otimização da outorga de uso da água. Dissertação (Mestrado em Engenharia Agrícola) Universidade Federal de Viçosa, Viçosa, 2006.

PETTERINI, F. C.. Mercado de água: como aconteceu nos EUA e como pode acontecer no Brasil. Interthesis, Florianópolis, v.15, n.1, p.130-143, 2018.

RIBAS, G. P. P.. O tratamento jurídico dos recursos hídricos no Brasil e nos Estados Unidos da América. Veredas do Direito, Belo Horizonte, v.13, n.27, p.179-207, 2016

RIBEIRO, M. A. F. M.; BARBOSA, D. L.; BATISTA, M. L. C.; ALBUQUERQUE, J. P. T.; ALMEIDA, M. A.; RIBEIRO, M. M. R. Simulação da prioridade de uso das águas superficiais como um critério para o instrumento da outorga. Revista Brasileira de Recursos Hídricos, v.19, n.2, p.135-145, 2014.

RIBEIRO, M. M. R.; LANNA, A. E. L.. Instrumentos Regulatórios e Econômicos: Aplicabilidade à Gestão das Águas e à Bacia do Rio Pirapama, PE. Revista Brasileira de Recursos Hídricos, v.6, n.4, p.41-70, 2001.

SANTOS, P. V. C. J.; CUNHA, A. C.. Outorga de recursos hídricos e vazão ambiental no Brasil: perspectivas metodológicas frente ao desenvolvimento do setor hidrelétrico na Amazônia. Revista Brasileira de Recursos Hídricos, v.18, n.3, p.81-95, 2013.

SIMPLÍCIO, C. G.; FARIA, L. V.. Outorga de direito de uso dos recursos hídricos e suas implicações na atividade agropecuária. Revista Referência, v.2, n.2, 2016.

TOCANTINS. Decreto n. 2.432, de 6 de junho de 2005. Regulamenta a outorga do direito de uso de recursos hídricos. Palmas: DOE, 2005.

TOCANTINS. Secretaria do Meio Ambiente e Recursos Hídricos. Manual de Outorga. Palmas: DOE, 2016.

A CBPC - Companhia Brasileira de Produção Científica (CNPJ: 11.221.422/0001-03) detém os direitos materiais desta publicação. Os direitos referem-se à publicação do trabalho em qualquer parte do mundo, incluindo os direitos às renovações, expansões e disseminações da contribuição, bem como outros direitos subsidiários. Todos os trabalhos publicados eletronicamente poderão posteriormente ser publicados em coletâneas impressas sob coordenação da Sustenere Publishing, da Companhia Brasileira de Produção Científica e seus parceiros autorizados. Os (as) autores (as) preservam os direitos autorais, mas não têm permissão para a publicação da contribuição em outro meio, impresso ou digital, em português ou em tradução. 